\title{
Correction to: Predictors of intracranial hemorrhage in adult patients on extracorporeal membrane oxygenation: an observational cohort study
}

Alexander Fletcher-Sandersjöö ${ }^{1,2^{*}}$, Jiri Bartek Jr ${ }^{1,2,3}$, Eric Peter Thelin ${ }^{2,4}$, Anders Eriksson ${ }^{5}$, Adrian Elmi-Terander ${ }^{1}$, Mikael Broman ${ }^{5,6}$ and Bo-Michael Bellander ${ }^{1,2}$

Correction to: J Intensive Care (2017) 5:27

https://doi.org/10.1186/s40560-017-0223-2

In the original publication of this article [1], the first author's name should be changed from Alexander Fletcher Sandersjöö to Alexander Fletcher-Sandersjöö. The family name of the author is Fletcher-Sandersjöö.

The authors sincerely apologize for the inconvenience caused to the readers.

\begin{abstract}
Author details
'Department of Neurosurgery, Karolinska University Hospital, Stockholm, Sweden. ${ }^{2}$ Department of Clinical Neuroscience, Karolinska Institutet, Stockholm, Sweden. ${ }^{3}$ Department of Neurosurgery, Copenhagen University Hospital Rigshospitalet, Copenhagen, Denmark. ${ }^{4}$ Division of Neurosurgery, Department of Clinical Neurosciences, Cambridge Biomedical Campus, University of Cambridge, Cambridge, UK. ${ }^{5}$ ECMO Center Karolinska, Department of Pediatric Perioperative Medicine and Intensive Care, Karolinska University Hospital, Stockholm, Sweden. ${ }^{6}$ Department of Physiology and Pharmacology, Karolinska Institutet, Stockholm, Sweden.
\end{abstract}

Published online: 03 January 2020

\section{Reference}

1. Fletcher-Sandersjöö, et al. J Intensive Care. 2017;5:27. https://doi.org/10. 1186/s40560-017-0223-2.

\footnotetext{
The original article can be found online at https://doi.org/10.1186/s40560017-0223-2

* Correspondence: alexander.fletcher-sandersjoo@stud.ki.se

${ }^{1}$ Department of Neurosurgery, Karolinska University Hospital, Stockholm, Sweden

${ }^{2}$ Department of Clinical Neuroscience, Karolinska Institutet, Stockholm,

Sweden

Full list of author information is available at the end of the article
}

(c) The Author(s). 2020 Open Access This article is distributed under the terms of the Creative Commons Attribution 4.0 International License (http://creativecommons.org/licenses/by/4.0/), which permits unrestricted use, distribution, and reproduction in any medium, provided you give appropriate credit to the original author(s) and the source, provide a link to the Creative Commons license, and indicate if changes were made. The Creative Commons Public Domain Dedication waiver (http://creativecommons.org/publicdomain/zero/1.0/) applies to the data made available in this article, unless otherwise stated. 